\title{
Det vanskelige steget! \\ Om unge homofile sitt steg "ut av skapet"
}

\author{
Jan Dalchow og Trond W interkjær i samtale med $\mathrm{N}$ ils-Petter H auge
}

I 1996 kom den fyrste dokumentaren i Noreg om homofil ungdom. Filmen "Jeg elsker hvem jeg vil" har skapt sterke og mange positive reaksjonar på filmfestivalar, så vel som hos einskildmenneske som endeleg opplevde å sjå og høyre andre på eigen alder setje ord på forbodne kjensler og taus kjaerleik. - Å kome "ut av skapet" handlar i stor grad om å bli akseptert av andre, og kanskje like vanskeleg: å skulle godta og forstå seg sjølv som homofil eller lesbisk. Det seier Jan Dalchow og Trond Winterkjaer, produsent og regissør for filmen. I denne samtalen drøftar dei mellom anna kva konsekvensar filmen har fått for unge homofile og lesbiske. Slik blir det ein samtale om kjoerleik og respekt, og - saknet etter dette.

\section{“Jeg elsker hvem jeg vil"}

Idéen til filmen fekk Jan Dalchow i ein alder av 25 år då han kom i kontakt med det organiserte homsemiljøet i 0 slo gjennom U ngdomsgruppa knytt til Landsforeningen for lesbisk og homofil frigjøring (LLH). $\mathrm{H}$ an var i slutten av sin «kome ut-fase», og møtte endeleg eit ope miljø med ungdom ned i 15-årsalderen som levde ut sine kjensler utan merkbar frykt for å bli mobba eller utstøytt i sin omgangskrets. Dette møtet utløyste ambivalente kjensler hos Dalchow. I prosjektrapporten til filmen skriv han at han blei "glad for å se hvor godt disse ungdommene hadde det med seg selv, trist for at jeg ikke kom i kontakt med et slikt miljø da jeg var tenåring. Det å bli spart for de lidelser det medfører å skjule sin seksuelle legning vil gjøre livet svært mye enklere for mange unge som har nok med de vanlige tenăringsproblemene." Der og då bestemte Jan Dalchow seg. I sitt virke ville han arbeide for å informere om unge homofile og deira levekår, og slik gje andre som ennå ikkje har "kome ut", nokon å identifisere seg med. Film blei $D$ alchow sitt medium. Dette medium er ikkje minst veleigna når ein skal formidle noko til ei "usynleg" gruppe, til utrygge sjeler som ønskjer å få sin første kunnskap i trygge omgjevnader.

$M$ ange brev, kommentarar og lesarinnlegg $i$ aviser har forvissa Jan og Trond om at filmen har påverka unge homofile og lesbiske sin kvardag. - Filmen blir nytta som eit kommunikasjonsmiddel, seier dei. Ved å sjå filmen saman med foreldrene opplever unge å få visualisert sine umoglege tankar. Filmen talar eit språk mange foreldre har forstått, noko som har skapt rom for ettertanke og forsoning. - I tillegg til at filmen slik har gjort det lettare for unge å «kome ut av skapet», har han også gjeve mange foreldre mot og støtte til å kome ut samstundes - til å vedgå at dei er homofile sine foreldre.
- Filmen blir som ein terapitime for foreldrene, og dannar samstundes dagsorden for den uunngåelege samtalen som ventar, seier dei.

$M$ en dette er ikkje enkelt, det veit dei. Dei fleste foreldre tenkjer tradisjonelt og forventar å få sine barnebarn. M ange unge opplever også det å synleggjere seg sjølv som homofil som dramatisk, sjølv om dei får støtte frå omgjevnadene. - Det kan opplevast som ein ikkje-reversibel tilstand der livet aldri meir kan bli "normalt". Ein vil ofte kjenne seg full av skam og ekkel for det ein har gjort mot seg sjølv, foreldrene og andre. Eige dømmande homosyn blir automatisk kopla inn. N oko ein har fornekta og flykta frå, ikkje minst på grunn av kameratane si haldning til homofili, kan ikkje lenger fornektast, seier Jan. Trond er einig. - Ein kjenner seg bunden til eit framtidig liv i skam, med alt det kan utløyse av akutt og langvarig smerte - farleg smerte. Sidan dette er ei kjensle som ligg rotfesta hos mange i denne fasen, er det så viktig å få ei rask stadfesting frà omgjevnadene som døyver desse tankane. Ikkje berre frå forel drene, men frå mange partar! Kva kan så helsepersonell gjere for å bidra positivt $i$ "kome ut"-prosessen?

\section{Helsepersonell sitt møte med unge homofile}

Tenk deg situasjonen. Ein ungdom sit føre deg på ein stol med eit risp i handa. $\mathrm{H}$ an er stille og brydd og ønskjer ikkje augekontakt. Du forstår raskt at han ikkje hadde som målsetjing å døy med handlinga si. Det var heller noko han ville seie med ho, noko som ikkje kunne seiast med ord. M en kva? Trond og J an tenkjer gjennom korleis dette møtet bør vere til det beste for "pasienten". - U nngå i alle fall å stille spørsmål om han er homofil tidleg i samtalen. Det er fint at ein er direkte og open, men gje ungdomen høve til å bli trygg på deg fyrst. $0 \mathrm{~m}$ denne tryggleiken ikkje er sådd i samtalen i det spørsmålet blir stilt, vil dei alle fleste svare nei. Start heller med å surfe etter ulike sannsynlege årsaker. I denne alderen er situasjonar som inneber tap og sakn, særskilt vanskelege å handtere. Kjærleiksproblem er truleg den situasjonen som oftast framprovoserer slike opplevingar for unge. Derfor er det naturleg å innleiingsvis snakke generelt om kjærleiken. Du bør medvite sikre deg at han opplever at du er til å stole på. Dette inneber at du ikkje berre aksepterer ulike former for kjærl eik, men at du forstår desse formene. $\mathrm{N}$ år han synest trygg på deg, så spør direkte: Er du glad i ein annan gut? Ikkje pakk spørsmålet inn i tåkete ordelag, dette gjer han berre meir sikker på at homofili bør dekkjast over.

Y mtar ungdomen frampå at han har kjensler retta mot ein annan gut, unngå dømmande ord eller usikre blikk. $\mathrm{H}$ an er usikker og sjølvdømmande nok som det er. Kom han heller i møte, og la han få snakke om det som tyngjer. U nngå også å kome med enkle og raske løysingar på "problemet". Verken eit program der han skal helbredast frå si legning eller eit halleluja der han einsidig blir møtt med ei positiv tru på at "nu vil alt gå så meget bedre", er produktivt. I denne fasen er han svært sårbar og "søkjande", og farleg lett å motivere til det meste. Dette faktum bør møtast med respekt, og ikkje utnyttast destruktivt. Ta utgangspunkt i det han fortel, og drøft med han kva støtte og hjelp han treng. $\varnothing$ nskjer han hjelp til å seie det til sine næraste? Bør han kontakte eit trygt homofilt miljø der han kan byggje opp sjølvtillit før han seier noko til andre?

Problemet er at mange helsearbeidarar, som folk flest, ikkje veit nok om homofili til å stille dei rette spørsmåla. Eit minstekrav må vere at ein kjenner terminologien, altså at ein veit kva homofili er og ikkje er. - M ytar om homofile kan gjere at ein vegrar seg mot å ta opp emnet. - Til dømes var det ein sjukepleiar som på eit 


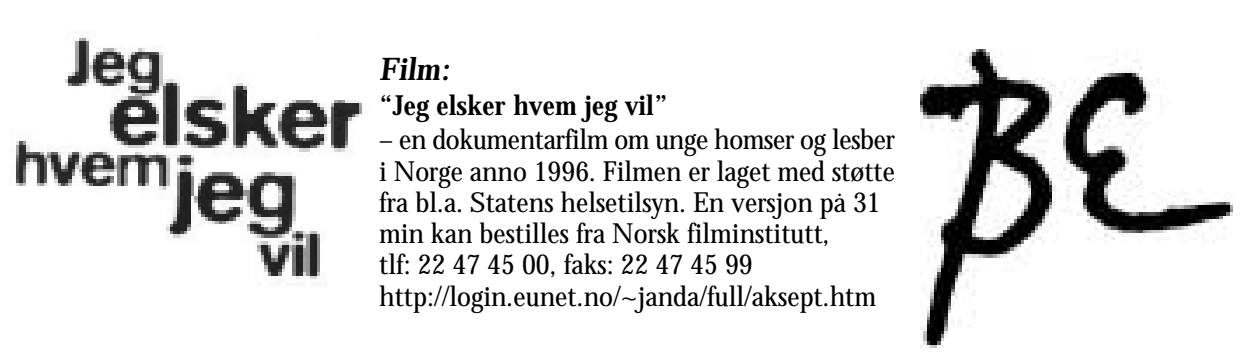

kurs spurte meg om eg likte å kle meg i dameklede ettersom eg er homofil, seier Trond. $\mathrm{H}$ an ler, men alvoret kjem raskt attende: - Det er viktig å spreie kunnskap om homofili blant helsepersonell, slik at hjelparen kan få bygt opp under sin eigen tryggleik forut for møte med unge homofile. Fyrst kan ein gjennom kurs eller på eige initiativ setje seg inn i homofile sine levekår på godt og vondt, t.d. ved å lese "Vite for å forstå". Vidare kan ein kontakte LLH og få namnet på ei eventuell lokalgruppe i nærdistriktet, eller kanskje finst det ei ope kyrkjegruppe? Slik kunnskap utgjer viktige handlingsalternativ for den unge. Kunnskapen hevar også meistringsnivået til hjelparen, noko som senkar terskelen for det å våge å bry seg.

\section{Andre sentrale aktørar i "kome ut"-prosessen}

- Særleg vaksenmodellar unge ikkje kan velje seg bort i frå, til dømes ungdomsskul elæraren, er viktige for å sikre ein best mogleg "kome ut"- prosess. Lærarar må ta opp homofili som tema i faga, og på ein naturleg måte. Ein kan også bestille skuleversjonen av den før omtala filmen frå N orsk Filminstitutt, samt ei vedlagd Iærarrettleiing. $\AA$ vise denne filmen for deretter å følgje opp med ein diskusjon i klassen, kan ha mange fordelar. M ellom anna har Trond og Jan fătt tilbakemeldingar som stadfestar at unge heterofile har fått eit langt meir balansert syn på homofile og homofili etter å ha sett filmen. Dette i seg sjølv er eit viktig signal: K valitetsinformasjon skapar grunnlag for forståing blant dei som skal omgå den homofile etter synleggjeringa. Vidare ein diskusjon i klassen om homofili, gjerne saman med ein som har "stått fram", vil også kunne gje den skjulte homofile eit vink om kven det er i klassen som synest å "forsvare" homofili. Eit slikt innsyn kan danne grunnlaget for ei fyrste samtale med vener om vanskelege kjensler. M en uansett einskildtiltak - viktigast er det i det daglege ikkje å stigmatisere homofili eller homofile i klassen, i konfirmantgruppa og så bortetter.

\section{Kva kan synlege homofile gjere?}

A t stadig fleire vel å stå fram som homofile eller lesbiske, gjer det til ein viss grad lettare for unge å akseptere si legning. Ein føresetnad i så måte er at ein etablerer trygge miljø der unge homofile kan oppleve å få eit positivt fyrsteinntrykk av si nå erkjente referansegruppe. Jan meiner at til dømes U ngdomsgruppa i O slo er eit slikt positivt miljø. Problemet er berre at det finst få grupper rundt om i N oreg. Dette gjer ikkje situasjonen lett for unge homofile i distrikta som ønskjer å stå fram, i det dei manglar synlege referansepersonar og -miljø. Dermed er det ikkje uventa, seier Jan, at det finst så mange seksuelle flyktningar i dei største byane. M en kva med dei som blir attende? Det blir ei viktig utfordring for LLH i framtida å etablere eit synleg kontaktnett ute i distrikta, men dette krev ressursar som ikkje finst. Slik blir det ikkje berre eit spørsmål for LLH, men eit offentleg spørsmål. - O g med den regjeringa vi har nå...Jan stoggar.

Det triste er kva som skjer nàr det ikkje er etablert trygge, sunne og opne nettverk i nærmiljøet, eller når ungdom ikkje kjem i kontakt med slike miljø. Dessverre er det altfor mange unge som får sitt fyrste møte med homsemiljøet på sjekkemarknaden, noko det ofte blir dårlege erfaringar av. Tilværet som "seksuelt objekt" i visse homsemiljø kan etter kvart rive ned alt som heiter sjølvrespekt og sjølvbilete. Derfor, seier dei - det handlar ikkje berre om å kome ut av skapet til rett tid, men også om å kome ut på rett stad! U nge homofile treng medmenneske som kan hjelpe til med å sikre at så skjer.

I utgangspunktet er det uinteressant om denne hjelpa kjem frå profesjonelle hel searbeidarar. Viktigare er det at hjelparen er eit profesjonelt medmenneske.

\section{Homofili i det nye tusenåret}

Ei stortingsmel ding om lesbiske og homofile sine levekår og livskvalitet er under planlegging. Fleire dokumentarar om homofile sin situasjon i dette tolerante samfun nets vi hevdar å ha nå i år 2000, er under produksjon. K vifor må dette til? Jan Dalchow funderer litt før han avsluttar: - N år det gjeld dette homospørsmålet, trur eg veldig mange kompliserer det heile unødig. A It er det same - kjenslene, problema, gledene - som eitkvart menneske kjenner på når det handlar om livet, om det å el ske og å bli elska. Dette handlar ikkje primært om kjønn, men om kjærleik. N år eg snakkar om homofil kjærleik, snakkar eg ikkje homosak, men om kjenslelivet mitt. Er det så vanskeleg å forstå?
Film:

"Be - skitne, syndige meg"

en dokumentarfilm som avdekker kirkelig undertrykkelse av homofile, og viser konsekvenser av hva undertrykkelsen fører til for enkeltpersoner. Produsenter: Ivan G asparini og Jan Dalchow. Regi: Trond W interkjær og Jan Dalchow. Filmen vises for første gang på TV 2 lørdag 18. mars kl 21.20. Senere i år vil den også bli vist på SVT og DR. Kan bestilles fra N FI. http://zip.to/be/

Jan spaknar. H an veit så altfor godt at det finst sterke krefter i samfunnet som definerer homofili som noko sjukleg. I dokumentarfilmen "Be - skitne, syndige meg", som blir synt på TV 2 18. mars, gjev Jan og Trond eit nytt innsyn i nokre av desse kreftene.

\section{Aktuelle referanser:}

Benum, Vår / Friis, Eva / O fferdal, A sle (red.). Vite for å forstå: 10 artikler om homoseksualitet og lesbiske og homofiles livsvilkår i N orge i dag. - O slo 1997. - 177 s. Pris kr 139, kan bestilles fra LLH.

Friis, Eva. Selvmord og selvmordsforebygging blant homofile og lesbiske.

Suicidologi 1998 ; 3 (3): 18-19

H egna, Kristinn / Kristiansen, $\mathrm{H}$ ans W / M oseng, Bera U Istein. Levekår og livskvalitet blant lesbiske kvinner og homofile menn. 0 slo : N orsk institutt for forskning om oppvekst, velferd og aldring. N OVA -rapport 1/1999. Kan bestilles fra N OVA, M unthesgt. 29, 02600 slo, tlf.: 22541200

O fferdal, A sle. Selvmord og selvmordsforsøk blant unge homofile menn. Forekomst sett $\mathrm{i}$ lys av homonegativisme og identitetutvikling: et litteraturstudium. - Bergen 1995. H ovedoppgave ved U niversitetet i Bergen, Det psykologiske fakultet. Kan bestilles hos O fferdal, tlf. 22933527.

L andsforeningen for lesbisk og homofil frigjøring (LLH ). Pb. 6838 - St. O lavs plass, 01300 slo, tlf: 223619 48, http://www.llh.no

\section{L øvetann - temanummer om selvmord}

- 1998, nr. 2. Tidsskriftet kan bestilles fra redaksjonen, Pb. 6745 - St. O lavs plass, 01300 slo, tlf: 223600 78, faks: 222061 75,

e-post: lovetann@sn.no

Et utvalg artikler kan leses på Internett:

http://www.med.uio.no/ipsy/ssff/lovetann.htm

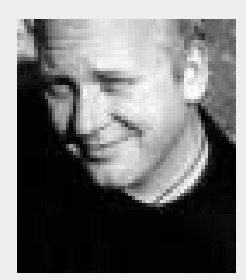

Jan D alchow har i 11 år jobbet som programmedarbeider, teknisk leder og reklameprodusent i Radio 1, og også med musikkproduksjon. I de senere årene har han jobbet mest med TV-, film- og videoproduksjon, og har vært produsent for og initiativtaker til "Jeg el sker hvem jeg vil". H an er i dag freelancer hovedsakelig for media og reklamebransjen.

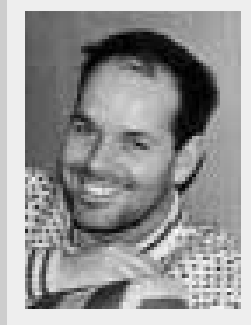

Trond Winterkjær er regiog filmutdannet. $\mathrm{H}$ an har jobbet bl.a. som fotoredigerer ved Forsvarets rekrutteringsog mediesenter. $\mathrm{H}$ an arbeider p.t. som produsent i TV N orge. H an var regissør for "Jeg el sker hvem jeg vil".

$\mathbf{N}$ ils-Petter $\mathbf{H}$ auge er forsker ved

Seksjon for selvmordsforskning og -forebygging. 